\title{
Do beta-adrenoceptor blocking drugs cause retroperitoneal fibrosis?
}

\author{
JOHN P PRYOR, WINIFRED M CASTLE, DAVID C DUKES, JOSEPH C SMITH, \\ MICHAEL E WATSON, JOHN L WILLIAMS
}

\begin{abstract}
The aetiology of retroperitoneal fibrosis is unknown. From time to time different drugs have been suggested as a cause, including beta adrenoceptor blocking agents. The notes of 100 hospital inpatients in whom retroperitoneal fibrosis had been diagnosed were surveyed to identify the date of onset of symptoms, the drugs prescribed before then, and the blood pressures on admission. Seventy one patients had diastolic pressures on admission of $90 \mathrm{~mm}$ $\mathrm{Hg}$ or more and 53 of these had pressures of at least $100 \mathrm{~mm} \mathrm{Hg}$ despite 14 of the patients taking antihypertensive drugs at the time. Six patients had received beta-adrenoceptor blocking agents before the onset of symptoms and a further 24 received them subsequently. In particular, three patients continued treatment for at least. six years after the diagnosis was made and surgery performed, without suffering a recurrence of retroperitoneal fibrosis.

Besides beta-adrenoceptor drugs, diuretics and other hypotensive drugs were taken in amounts reflecting the
\end{abstract}

Institute of Urology, London WC2H 8JE

JOHN P PRYOR, MS, FRCS, dean and consultant urologist

Imperial Chemical Industries PLC, Alderley Park, Macclesfield, Cheshire SK10 4TG

WINIFRED M CASTLE, MD, MFCM, medical adviser

Walsgrave Hospital, Coventry CV2 2DX

DAVID C DUKES, MD, FRCP, consultant physician

Churchill Hospital, Oxford OX3 7LJ

JOSEPH C SMITH, MS, FRCS, consultant urologist

Preston Royal Infirmary, Preston, Lancashire PR1 6PS

MICHAEL E WATSON, PHD, FRCS, consultant urologist

Royal Hallamshire Hospital, Sheffield S10 2JF

JOHN L WILLIAMS, FRCS, consultant urologist

Correspondence to: Mr J P Pryor. pattern of drug use among hypertensive patients generally. Rather than being causal agents, the antihypertensive drugs were probably being used to treat hypertension associated with the retroperitoneal fibrosis, and our findings suggest that beta-adrenoceptor blocking agents do not cause retroperitoneal fibrosis.

\section{Introduction}

Ormand, who described retroperitoneal fibrosis in 1948, suggested in 1965 that the disease may be related to therapeutic agents. ${ }^{1}$ Since then different drugs have been specifically mentioned: methysergide, ${ }^{8}$ ergotamine, ${ }^{3}$ hydralazine, ${ }^{4}$ methyldopa, ${ }^{b}$ analgesics (particularly phenacetin), ${ }^{\circ}$ and, most recently, beta-adrenoceptor blocking agents such as atenolol, ${ }^{7}{ }^{8}$ metoprolol, ${ }^{9}$ oxprenolol, ${ }^{10}$ propranolol, ${ }^{11}{ }^{12}$ and solatol. ${ }^{13}$ The Committee on Safety of Medicines has asked for reports of retroperitoneal fibrosis when any drug, but particularly a betaadrenoceptor blocking agent, is suspected of having a causative role. ${ }^{14}$ In an attempt to put such reports into perspective we have collected information, particularly drug histories, from the case notes of 100 patients diagnosed as having retroperitoneal fibrosis.

\section{Patients and methods}

We analysed the hospital notes of 100 patients who had been admitted and in whom retroperitoneal fibrosis had been diagnosed. The patients came from hospitals in Coventry, Manchester, Newcastle on Tyne, Nottingham, Oxford, and Sheffield, and from King's College, St Mary's, and St Philip's hospitals in London. Only a few patients with either no recorded drug history or a diagnosis made before 1966, had to be excluded, as beta-adrenoceptor blocking agents were not available before 1966 . In the 100 patients whom we finally selected the year of diagnosis ranged from 1966 to 1981 (median 1978) and in all but eight patients the diagnosis was confirmed surgically. The information was transcribed on to a standard record form and included details of the patient, medical and drug histories, symptoms, dates of both onset of symptoms and diagnosis, and recorded blood pressure on admission. Seventy patients were men and the mean age at diagnosis was 56 years (range 18-78). 


\section{Results}

The medical history was unremarkable. Table I gives patients' symptoms on presentation, the most common of which was pain in the back or loins. The case notes stated a negative drug history in 16 cases. The known drugs taken by the remaining 84 patients before the onset of symptoms of retroperitoneal fibrosis are shown in table II. Four patients had taken propranolol (for $5,4,2 \frac{1}{2}$, and $1 \frac{3}{4}$ years) and of these the patient who had taken it for $2 \frac{1}{2}$ years had also taken practolol for

TABLE I-Symptoms in 100 patients with retroperitoneal fibrosis

\begin{tabular}{lclc}
\hline & $\begin{array}{c}\text { No of } \\
\text { patients }\end{array}$ & $\begin{array}{c}\text { No of } \\
\text { patients }\end{array}$ \\
\hline Pain in abdomen or back & 85 & Testicular pain & $9 / 70$ \\
Polyuria & 44 & Testicular swelling & (or hydrocoele) \\
Anorexia & 38 & Thirst & $8 / 70$ \\
Loss of weight & 37 & Abdominal fullness & 9 \\
Vomiting & 27 & 8 \\
Constipation & 24 & General ill health & 7 \\
Nausea & 23 & Anaemia & 7 \\
Tiredness & 21 & Feverishness & 8 \\
Headache & 13 & Diarrhoea & 5 \\
Oedema & 10 & Weight gain & 5 \\
\hline
\end{tabular}

TABLE $\mathrm{II}-K$ nown drugs taken by patients before and after the onset of symptoms of retroperitoneal fibrosis

\begin{tabular}{|c|c|c|c|}
\hline & $\begin{array}{l}\text { Before symptoms } \\
\qquad(\mathrm{n}=84)\end{array}$ & $\begin{array}{l}\text { After symptoms } \\
(\mathrm{n}=100)\end{array}$ & Total \\
\hline \multicolumn{4}{|l|}{ Beta-adrenoceptor blocking agents: } \\
\hline Propranolol & 4 & 9 & 13 \\
\hline Atenolol & 0 & 11 & 11 \\
\hline Oxprenolol & 2 & 5 & 7 \\
\hline Metoprolol & 0 & 5 & 5 \\
\hline Labetalol & 0 & 3 & 3 \\
\hline Practolol & 1 & 0 & 1 \\
\hline \multicolumn{4}{|l|}{ Other antihypertensive agents: } \\
\hline $\begin{array}{l}\text { Methyldopa } \\
\text { Methe agcits. }\end{array}$ & 6 & 7 & 13 \\
\hline Hydralazine & 1 & 3 & 4 \\
\hline Prazosin & 0 & 1 & 1 \\
\hline Clonidine & 1 & 2 & 3 \\
\hline \multicolumn{4}{|l|}{ Diuretics: } \\
\hline Frusemide & 2 & 6 & 8 \\
\hline Moduretic & 1 & 1 & 2 \\
\hline Bendrofluazide & 3 & 6 & 9 \\
\hline Cyclopenthiazide & 5 & 3 & 8 \\
\hline Chlorthalidone & 1 & 0 & 1 \\
\hline Potassium supplements & 8 & 5 & 13 \\
\hline \multicolumn{4}{|l|}{$\begin{array}{l}\text { Migraine treatment: } \\
\text { Mint }\end{array}$} \\
\hline Pizotifen & 1 & 0 & 1 \\
\hline Ergotamine & i & 0 & i \\
\hline \multicolumn{4}{|l|}{ Anti-inflammatory analgesics: } \\
\hline $\begin{array}{l}\text { Indomethacin and related } \\
\text { compounds }\end{array}$ & 3 & 0 & 3 \\
\hline Arylcarboxylic acid derivatives & 1 & 4 & 5 \\
\hline \multicolumn{4}{|l|}{ Analgesics: } \\
\hline Distalgesic & 8 & 1 & 9 \\
\hline Anadin & 4 & 4 & 8 \\
\hline Codeine & 2 & 1 & 3 \\
\hline Solpadeine & 1 & 0 & 1 \\
\hline Paracetamol & 2 & 1 & 3 \\
\hline Pentazocine & 0 & 3 & 3 \\
\hline DF 118 & 1 & 1 & 2 \\
\hline \multicolumn{4}{|l|}{ Others ( $>3$ each before symptoms): } \\
\hline Trinitrates & 5 & 1 & 6 \\
\hline Diazepam & 6 & 0 & 6 \\
\hline Iron & 4 & 1 & 5 \\
\hline Miscellaneous ( $\leqslant 3$ before symptoms) & 61 & 34 & 95 \\
\hline Total & 135 & 118 & 253 \\
\hline
\end{tabular}

two months before taking propranolol. A further two had taken oxprenolol (for 12 and 5 years). Six patients had taken methyldopa and one hydralazine; 12 had taken various diuretics, of whom eight had also been given potassium supplements.

One patient started taking metoprolol at about the same time that clinical symptoms of retroperitoneal fibrosis appeared, and a further 24 patients were prescribed beta adrenoceptor agents after the onset of symptoms of retroperitoneal fibrosis. Table II also shows the drugs taken by the 100 patients after the onset of symptoms. In particular, three patients had received beta adrenoceptor blocking drugs for at least 6 years after retroperitoneal fibrosis had been diagnosed and surgical treatment undertaken. In one patient propranolol had been given for $6 \frac{1}{2}$ years followed by atenolol for $2 \frac{1}{2}$ years, in another propranolol had been given for 6 years, and in the third propranolol had been given for 3 years followed by oxprenolol for a further 3 years. The medical records of these three cases state that there was no radiological or other evidence of recurrence throughout this period of treatment with beta-adrenoceptor blocking agents.

Details of blood pressure on admission were available for 96 patients, and only 35 patients were not hypertensive (blood pressure less than
$160 / 90 \mathrm{~mm} \mathrm{Hg}$ ) at the time of admission to hospital. Seventy one patients had a diastolic pressure of at least $90 \mathrm{~mm} \mathrm{Hg}$ and in 53 it was at least $100 \mathrm{~mm} \mathrm{Hg}$. Fourteen patients were receiving antihypertensive drugs at the time the measurements were made.

\section{Discussion}

There are dangers in drawing conclusions from data taken retrospectively from patients' hospital records. One problem is the confirmation of diagnosis. Ninety two patients in this study had their diagnosis confirmed because they underwent surgical exploration to exclude malignancy or relieve ureteric obstruction. A second general problem with restrospective case note reviews is that the drug histories recorded in hospital notes are unlikely to be completely accurate. As treatment with certain drugs is a recognised aetiological factor in retroperitoneal fibrosis, however, physicians are likely to ask about drugs taken by patients with retroperitoneal fibrosis. The possibility of omission was further reduced because the records of drug treatment were often duplicated as more than one specialist or hospital became concerned with the management of each patient.

The common symptoms of the disease reported in our series, including pain, anorexia, and weight loss, are characteristic. ${ }^{15}$. Hypertension is thought to be a factor associated with retro- $\mathscr{C}^{\circ}$ peritoneal fibrosis by some $e^{41617}$ but not others. ${ }^{18} 19$ Mundy et al $\underset{\omega}{\oplus}$ have recently shown that 17 out of 36 patients with retroperitoneal fibrosis presented with hypertension, that this was not always due to the obstructive uropathy, and that in some patients it was progressive despite treatment. ${ }^{20}$ Some believe that an $\omega$ association between antihypertensive drugs such as beta- $\mathscr{D}$ adrenoceptor blocking agents and retroperitoneal fibrosis is coincidental rather than causal. ${ }^{21}{ }^{22}$ Retroperitoneal fibrosis often causes hypertension, usually before the underlying disease is diagnosed, and understandably the disease is occasionally associated with the prior administration of hypotensive drugs. ${ }^{22}$ Hypertension was present in 61 of the patients, many of whom were treated with antihypertensive drugs such as diuretics, methyldopa, and beta-adrenoceptor blocking agents.

Beta-adrenoceptor blocking agents are of particular interest because practolol is known to have caused sclerosing peritonitis. Sclerosing peritonitis, however, which occasionally occurred after two to three years' treatment with practolol, is entirely different from retroperitoneal fibrosis. Histologically the densely fibrotic areas of collagen with distinct areas of cell infiltration, lymphoid follicles, and plasma cells in retroperitoneal fibrosis ${ }^{16}$ are not characteristic of the sclerosing peritonitis induced by practolol. Retroperitoneal fibrosis occurs behind the peritoneum, but sclerosing peritonitis affected only the visceral peritoneum, and the retroperitoneal tissues were never reported as having been affected. ${ }^{23}$ Other organs affected in the practolol syndrome were the skin, conjunctiva, ears, pleura, and pericardium. ${ }^{23}$ These sites are different fron those which are occasionally affected by idiopathic retroperitoneal fibrosis- 9 namely, the mediastinum, aorta, thyroid gland, orbit, and gall $N$ bladder. ${ }^{24}$ No patient in our series of 100 cases of retroperitoneal fibrosis had the psoriasiform rash or eye lesions that sometimes accompanied practolol toxicity.

A survey of drug use in hypertension conducted in 1978, the median year of our study, showed that, of 3598 patients receiving hypotensive treatment, $57^{\circ}$ were prescribed diuretics and $34 \%$ beta-adrenoceptor blocking agents-the same pattern of prescribing that we noted in our series of 100 patients. There are $\mathbb{D}$ no reports of retroperitoneal fibrosis in the large long term prospective studies of beta adrenoceptor drugs. ${ }^{25-28}$

Among the patients with retroperitoneal fibrosis, none had received methysergide, which was launched in the United Kingdom in 1962 but was never promoted to doctors, or $\varrho$ phenacetin. One of the two patients with migraine was treated 2 with ergotamine, the other with pizotifen. Eight patients had 8 taken dextropropoxyphene (Distalgesic) and six diazepam before the onset of the disease but this probably reflects only the fre- 
quency with which these drugs are prescribed in the general population.

This study has shown that beta-adrenoceptor drugs are unlikely to be causally associated with retroperitoneal fibrosis. Only six out of 31 patients who had received beta-adrenoceptor blocking agents did so before first complaining of symptoms considered to be due to their retroperitoneal fibrosis. Furthermore, three patients have taken beta-adrenoceptor drugs for over six years since the diagnosis had been confirmed without any evidence of recurrence of the fibrosis.

We thank the physicians and surgeons at the hospitals concerned in this study for their cooperation.

\section{References}

${ }^{1}$ Ormand JK. Idiopathic retroperitoneal fibrosis: a discussion of the aetiology. F Urol 1965;94:385.

${ }^{2}$ Graham JR. Methysergide for prevention of headache: experience in 500 patients over 3 years. $N$ Engl $\mathcal{F}$ Med $1964 ; 270: 67-72$.

${ }^{3}$ Stecker JF, Rawls HP, Devine CJ, et al. Retroperitoneal fibrosis and ergot derivatives. F Urol 1974;112:30-2.

${ }^{4}$ Kinder CH. Retroperitoneal fibrosis. 7 R Soc Med 1979;72:485-6.

${ }^{5}$ Iversen BM, Nordahl E, Thunold S, et al. Retroperitoneal fibrosis during treatment with methyldopa. Lancet $1975 ;$ ii :302-4.

${ }^{6}$ Lewis CT, Molland EA, Marshall VR, et al. Analgesic abuse, ureteric obstruction, and retroperitoneal fibrosis. $\mathrm{Br}$ Med $\mathcal{F}$ 1975;ii:76-8.

${ }^{7}$ Doherty CC, McGeown MG, Donaldson RA. Retroperitoneal fibrosis after treatment with atenolol. $\mathrm{Br}$ Med $\mathcal{F}$ 1978;ii :1786

${ }^{8}$ Johnson JN, McFarland JB. Retroperitoneal fibrosis associated with atenolol. Br Med f 1980;280:864.

${ }^{9}$ Thompson J, Julian DG. Retroperitoneal fibrosis associated with metoprolol. Br Med f 1982;284:83-4.

(1) McCluskey DR, Donaldson RA, McGeown MG. Oxprenolol and retroperitoneal fibrosis. $\mathrm{Br}$ Med $\mathcal{F} 1980 ; 281: 1459-60$.

"Pierce JR, Throstle DC, Warner JJ. Propranolol and retroperitoneal fibrosis. Ann Intern Med 1981;95:244.
${ }^{12}$ Henri L, Groleau M. Retroperitoneal fibrosis after treatment with propranolol. Drug Intelligence and Clinical Pharmacy 1981;15:696.

${ }^{13}$ Laakso M, Arvala I, Tervonen S, et al. Retroperitoneal fibrosis associated with sotalol. Br Med f 1982;285:1085-6.

${ }^{14}$ Committee on Safety of Medicines. Retroperitoneal fibrosis and beta adrenoceptor antagonists. Current Problems 1980;6:19.

${ }^{15}$ Koep L, Zuidema GD. The clinical significance of retroperitoneal fibrosis. Surgery 1977;3:250-7.

${ }^{16}$ Lepor H, Walsh PC. Idiopathic retroperitoneal fibrosis. $f$ Urol 1979;122: $1-6$.

17 Saxton HJ, Kilpatrick FR, Kinder CH, et al. Retroperitoneal fibrosis. A radiological and follow-up study of fourteen cases. $Q \mathcal{F}$ Med 1969; 38:159.

${ }^{18}$ Kerr HS, Suby HI, Videry A, et al. Idiopathic retroperitoneal fibrosis. Clinical experience with 15 cases. $\mathcal{F}$ Urol 1968;99:575.

${ }^{19}$ Arger PH, Stolz JL, Miller WT. Retroperitoneal fibrosis: an analysis of the clinical spectrum and roentgenographic signs. Am $\mathcal{F}$ Roentgen 1973;119: 812.

${ }^{20}$ Mundy AR, Kinder CH, Flannery JF, et al. Hypertension and thromboembolism in idiopathic retroperitoneal fibrosis. Br $\mathcal{F}$ Urol 1982;54: 625-7.

${ }^{21}$ Mitchinson MJ. Retroperitoneal fibrosis associated with metoprolol. $\mathrm{Br}$ Med f 1982;284:347.

${ }^{22}$ Gavin MJ, Castle WM, Cruickshank JM, et al. Retroperitoneal fibrosis associated with atenolol. $\mathrm{Br} \mathrm{Med} \mathcal{F} 1980 ; 280: 1227-8$.

${ }^{23}$ Nicholls JT. Adverse reactions of practolol. Ann Clin Res 1976;8:229-31.

${ }^{24}$ Mitchinson MJ. The pathology of idiopathic retroperitoneal fibrosis. $\mathcal{f}$ Clin Pathol 1970;23:681-9.

${ }^{25}$ Medical Research Council Working Party on Mild to Moderate Hypertension. Adverse reactions to bendrofluazide and propranolol for the treatment of mild hypertension. Lancet 1981 ;i :539-43.

${ }^{26}$ Beta-Blocker Heart Attack Trial Research Group. A randomised trial of propranolol in patients with acute myocardial infarction. 1. Mortality results. FAMA 1982;247:1707-14.

${ }^{27}$ Forrest WA. Slow-Trasicor (sustained release oxprenolol hydrochloride $160 \mathrm{mg}$ ) in the treatment of essential hypertension: a multicentre evaluation of 4400 patients. Br f Clin Pract 1977;31:181-6.

${ }^{28}$ Zacharias FJ, Cuthbertson PJR, Prestt J. Atenolol in hypertension: a study of long-term therapy. Postgrad Med $\mathcal{f}$ 1977;53:102-10.

(Accepted 2 fune 1983)

\title{
Epileptic seizures in a population of 6000
}

\section{I: Demography, diagnosis and classification, and role of the hospital services}

\author{
D M G GOODRIDGE，S D SHORVON
}

\begin{abstract}
A total of 122 patients with a history of non-febrile epileptic seizures were identified in a survey of 6000 persons from a single general practice. The lifetime prevalence was $20 \cdot 3 / 1000$ including single seizures and 17.0/1000 excluding single seizures; $5 \cdot 3 / 1000$ had active epilepsy. Diagnosis and classification of seizures in such a survey were difficult. Most patients were seen by a hospital specialist at some point, but hospital follow up was sporadic. Overall patient assessment and monitoring was poor.
\end{abstract}

There is a place for specialised epilepsy clinics that

Tonbridge, Kent

D M G GOODRIDGE, MB, MRCGP, general practitioner

National Hospital for Nervous Diseases and King's College Hospital, London SE5 9RS

$S$ D SHORVON, MD, MRCP, senior registrar in neurology

Correspondence to: $\operatorname{Dr} S \mathrm{D}$ Shorvon, Institute of Neurology, Queen Square, London WCIN 3BG. could be organised along the lines of the clinics for diabetes. These provide facilities for initial diagnosis and assessment, for planning long term management, for the selected follow up of difficult cases, and for referral for specific problems. Such a system would improve the long term care of patients with epilepsy.

\section{Introduction}

There are two major difficulties in the collection of accurate statistics in epilepsy. Firstly, the problem of patient selection. Most studies have been conducted from hospital clinics or institutions, and the resulting selection bias has, in our opinion, had an undue influence on many widely held views about diagnosis, management, and prognosis. In particular, patients with inactive or untreated epilepsy have been underrepresented. There have been a number of community based studies in the United Kingdom but most have been brief audits only, and even in the large scale surveys case selection has seldom been comprehensive. Thus some authors made use of retrospective morbidity registers ${ }^{1-3}$ or included only those who had had a recent fit or were taking anticonvulsant drugs, ${ }^{4-6}$ or both, those 